Conclusion The findings corroborate the minority stress theory, but they also generate new questions for researchers around when and why these inequalities emerge.

\section{P36 REGIONAL AND SOCIOECONOMIC DISPARITIES IN CHILD-TO-ADOLESCENT GROWTH TRAJECTORIES ACROSS GENERATIONS IN CHINA}

M Gao*, J Wells, L Li. GOS Institute of Child Health, University College London, London, UK

10.1136/jech-2020-SSMabstracts. 130

Background China has experienced rapid economic development since the 1990s, which has led to regional development inequality and could have an impact on the physical growth in Chinese children. Study about changes in growth trajectories across generations by region and socioeconomic (SES) factors is needed for informing policy to reduce inequality.

Methods We used the longitudinal data of 5118 children from China Health and Nutrition Survey (CHNS), who were born during 1981-2000 and whose height and weight were measured between 7-18y during 1991-2015. Four birth cohorts were derived (1981-85, 86-90, 91-95 and 96-2000) and mixed-effects fractional polynomial functions were applied to estimate child-to-adolescent growth trajectories by gender and cohort. Growth trajectories were further stratified by region (west, central, east and northeast) and urban/rural separately. Finally, both geographic and parental SES determinants (loghousehold income, paternal occupation and maternal education) were adjusted to estimate their association with childhood physical growth across cohorts.

Results Mean growth trajectories for height and BMI both shifted upwards across cohorts. The increase in BMI between the oldest (1981-85) and youngest (1996-2000) cohorts was $\sim 0.8 \mathrm{~kg} / \mathrm{m}^{2}$ at $9 \mathrm{y}$ (both genders) and remained in boys while narrowed in girls since late adolescence $\left(0.4 \mathrm{~kg} / \mathrm{m}^{2}\right.$ at $\left.17 \mathrm{y}\right)$. The increase in height widened pre-puberty $(5.7 \mathrm{~cm}$ in boys and $4.4 \mathrm{~cm}$ in girls at $13 \mathrm{y}$ ) and decreased thereafter. There were evident regional disparities in growth: gender-/cohort-specific BMI trajectories for children from the east region lay above those from the northeast region, followed by those for children from central/west areas. Height trajectory from northeast was the highest, followed by east, central and west regions. Growth increment across cohorts showed a similar regional pattern (e.g. children in west experienced the smallest growth increment across cohorts).

Urban children had higher BMI, were taller and had greater BMI increment while smaller height increment across cohorts than their rural counterparts, thus the urban-rural difference widened in BMI while narrowed in height across generations. Higher parental SES was associated with higher BMI and taller stature. The strength of relationship between maternal education with children's height was stronger in younger than in older cohorts.

Conclusion While children from urban and east region had higher BMI and greater BMI increment across cohorts, children from underdeveloped western China remain to be the shortest and should be maximized their potential of linear growth. The positive relationship between parental SES and children's BMI, which was opposite to the evidence in Western countries, may reflect a different mechanism in developing countries.

\section{P37 IDENTIFYING LONG-TERM, HIGH-DOSE USERS OF OPIOID DRUGS PRESCRIBED FOR CHRONIC NON- CANCER PAIN IN THE COMMUNITY}

1J Bailey*, ${ }^{2} S$ Gill, 1,2R Poole. 'School of Health Sciences, Bangor University, Bangor, UK;

${ }^{2}$ Betsi Cadwaladr University Health Board, NHS Wales, Wrexham, UK

\subsection{6/jech-2020-SSMabstracts. 131}

Background Studies of prescribing of opioid medication for chronic pain in the UK population show that it has increased sharply over the past 25 years. Although overall rates may have begun to decline recently, longer-term use and prescribing of 'strong' opioids continue to rise. Whilst analysis of data at a population level can tell us much about the use of these medications, an analysis at an individual level is needed to understand which patients, and how many, are at greatest risk from these potentially harmful drugs. Harms associated with these drugs are related to dose and length of use. The aim of this study was to develop a method to identify patients prescribed long-term, high doses of these drugs in the community and to assess the prevalence of such use.

Methods Details of all opioid prescriptions issued over a fourmonth period were collected from two demographically dissimilar GP practices. A total of 22,841 patients were registered at the practices, $1488(6.5 \%)$ of whom were prescribed opioids in the study period. Exhaustive examination of prescription data identified all patients who were prescribed oral morphine equivalent (ME) doses of $120 \mathrm{mg}$ /day or more in the census period. An examination of the prescription histories of these patients indicated those who had been prescribed opioids at this level for a year or more.

Results Every patient who met our criterion of $\geq 120 \mathrm{mg} /$ day ME for a year or more was being prescribed that level as a single drug of morphine, oxycodone or fentanyl, irrespective of opioid polypharmacy. Across the two practices, 1.71/1000 patients were identified as long-term, high-dose users of opioid medication for chronic non-cancer pain. Prevalence was similar in the two practices. Unadjusted extrapolation suggests that there are over 100,000 similar patients in the UK.

Conclusion This study provides a simple, reliable and practical means of identifying patients prescribed long-term high-dose opioid medication for chronic pain. These regimens are unlikely to provide additional pain relief but increase the risk of harm to patients. They have marked negative effects on day-to-day functioning and quality of life. Patients of interest can be identified simply through their use of three drugs as threshold doses and above. This can help in the further investigation of dysfunctional medication use; in establishing national and local prevalence; in monitoring service provision; and in identifying associated factors, such as social deprivation and regional variation.

\section{P38 EXPLORING THE EFFECT OF NATIONAL INSTITUTE OF HEALTH AND CLINICAL EXCELLENCE GUIDELINES ON PRESCRIBING BEHAVIOUR FOR CHILDHOOD ATOPIC ECZEMA IN PRIMARY CARE WITH AN INTERRUPTED TIME SERIES}

${ }^{1}$ LIW Schreuders*, ${ }^{2} \mathrm{SJ}$ Ersser, ${ }^{3} \mathrm{C}$ Thompson. 'Work and Employment Relations Division, Leeds University Business School, Leeds, UK; ${ }^{2}$ Faculty of Health and Social Science, Bournemouth University, Dorset, UK; ${ }^{3}$ School of Healthcare, University of Leeds, Leeds, UK

10.1136/jech-2020-SSMabstracts. 132 